\title{
Research On Ideological And Political Reform Of Tourism Management Specialty Course Under The Background Of Internet -- Taking Tourism Marketing As An Example
}

\author{
Jie $\mathrm{Hu}^{1}$ Shanshan $\mathrm{Li}^{2}$ Xiang $\mathrm{Gao}^{3 *}$ \\ 1,2,3 Jiangxi Tourism \& Commerce Vocational College, Nanchang, Jiangxi, 330000, China
}

\begin{abstract}
In the era of Internet big data in the 21st century, the Internet goes deep into all walks of life, which has brought a very profound influence on all walks of life. Nowadays, every industry with the blessing of the Internet can develop better and better. All walks of life are also more and more inseparable from the Internet. China is a large country rich in tourism resources, with the rapid development of the Internet, in the past ten years, China's tourism industry has also been rapid development. The concrete manifestation is the continuous increase of the number of tourists, the proportion of tourism income in the development of urban economy is increasing, and the tourism industry drives the consumption of the surrounding market. However, despite the hot development of tourism in China, we can not ignore the existing problems of tourism in China, such as deceiving consumers, market chaos, backward tourism products and a series of problems. Innovation market supervision and management system, maintain market order, so as to promote the development of tourism industry.
\end{abstract}

\section{Introduction}

In the 21 st century, the rapid development of the Internet has made people's lives fast and convenient, and all walks of life are late for the benefits of the rapid development of the Internet. In order to seize the market, China's famous tourist attractions use Internet tourism to create special online tourist attractions, such as Little Red Book, Ctrip, Shake tone and Weibo, which not only promote the popularity of tourism, but also make tourism more and more convenient. The new mode of "Internet tourism" drives the tourism industry, But how to make the tourism development of our country more and more standardized, how to make our Internet and tourism combine better and better, our country still has a long way to go, we should focus on opportunities, not afraid of challenges, Make our tourism industry better and better.

\section{At present, the development of tourism in China}

\subsection{Growing tourism}

In the first half of 2018, the number of domestic and overseas tourists in China exceeded the 5 billion mark for the first time, and the number of such tourists is still increasing. China is a big country in the world, from Changbai Mountain to Hainan Sanya from north Hainan
Sanya in the south, to major coastal cities in the east, to beautiful Xinjiang in the west, mysterious Tibet, vast territory and numerous scenery in recent years. The increasing number of overseas tourists also shows that China's tourist attractions and local culture are deeply rooted in the habits of foreign compatriots, and more and more international friends have some profound identity with our country. The increasing number of overseas tourists also indirectly shows that our country is an inclusive and open international country. The ideological and political theory expounds that culture is national and world, and our country fully shows this famous theory. The popularity of tourism in China has led to the development of the surrounding consumer industry, stimulated the domestic demand of our country, and brought cultural exchanges between regions and even countries[1].

\subsection{Growth in tourism revenues}

One of the troika driving our economy is domestic demand. The popularity of our tourism industry has led to the development of our economy. The income of the major tourist cities has increased in proportion to the income of the successful economic development, and the tourism industry is booming. In turn, the rapid development of the tourism industry has also led to the development of major platforms, among which the development of small red books, Ctrip, where to go these platforms can not be separated from the development of tourism. The development of tourism not only drives the

\footnotetext{
*Corresponding author's e-mail: 739960103@qq.com
} 
development of the whole national economy, but also gives birth to a series of additional industries. With the rapid development of tourism industry and the large increase of tourism consumption demand, the economic development of our country is getting better and better, and the level of our national economy has been guaranteed steadily. At the same time, the popularity of the tourism industry can not be separated from the policy blessing of the Party and the government. Nowadays, more and more cities begin to develop tourism and get rid of the shackles of industrial managers [2].

\subsection{Diversification of Tourism Patterns}

With the development of tourism in recent years, in order to seize the market and attract the number of tourists, all major tourist attractions have introduced different tourism models, which are no longer as simple as the previous tourism models. In recent years, the tourism industry has introduced new tourism models such as green tourism, self-driving tourism and one-day tour. These new models show that China's tourism industry is not satisfied with the present situation, has been pursuing innovation, pursuing sustainable development of tourism economy, and developing tourism innovation mode with the heart. Tourism industry in all parts of China has also started to introduce tourism with local characteristics, such as $\mathrm{Xi}^{\prime}$ an's marketing orientation is history, ancient capital, Changsha's marketing positioning is food, Hangzhou's marketing positioning is West Lake, network popular city, Chengdu's marketing positioning is cultural inclusiveness. The new model of "Internet tourism" has been very successful in recent years. As Dunhuang of the Silk Road, it grasps the construction of Belt and Road. Dunhuang murals and Dunhuang culture will be carried forward, and even in recent years has created Dunhuang Culture Festival, attracting a large number of tourists.

\section{Major Problems Faced by China's Tourism Industry}

\subsection{The tourism market is chaotic and government regulation is inadequate}

In recent years, major media have revealed a variety of tourism problems, the most common is the chaos of the tourism market, the biggest problems in the past year or two are Yulong Snow Mountain slaughter, Qingdao sky crab, Lijiang tourism was beaten, tour groups forced consumption. In particular, the emergence of various kinds of improper tour groups, in the name of low-price tourism, hundreds of playing four days and three nights, deceiving consumers from time to time, with the rapid development of tourism, The training of tourism talents can not keep up with the development of tourism industry. In the market, the pricing of tourism products is not uniform, all kinds of tourism products are overpriced, Guangzhou Changlong a pot of boiled water asking for 50 yuan, scenic spot tickets hotel accommodation is not clear price, especially when the holidays come, The hotels began to shout. Taking Guilin and Lijiang as examples, tour groups, under the banner of low prices, give huge concessions, but in essence, tour guides take tourists to play only two or three scenic spots. The rest of the time brought tourists into major consumer places, tour guides and businesses signed economic contracts, tour guides in order to achieve a certain economic purpose, and even forced consumers to buy goods. This is also the cause of disharmony between travel and tour guides and physical conflict. In recent years, it has become the norm for the tourism industry to cooperate with each other to seek benefits. This norm not only hurts consumers, but also hurts the tourism market in their own places. Good service can make tourism development better and better, poor service, tourism industry can only decline.

\subsection{Single tourism products, scarce quality products}

The biggest problem in the domestic tourism industry is the market chaos, the government supervision is not in place, there is also an important problem is that in the tourism market demand, China's tourism products are not diversified enough, inferior products more than high-quality products, whether based on culture or the emerging network popular cities, the market bought tourism products are too unified[3], simply can not reflect the connotation of the tourist city, Hangzhou is different, its modernization is very heavy, but in the tourism market, whether it is the Confucius Temple in Nanjing or the Royal Street in the Southern Song Dynasty in Hangzhou, the tourism products are the same, the same scarves, small toys without any difference. As long as the market has successfully marketed a scenic spot, the next tourist city will almost imitate the original city without any sense of innovation. For example, every city has an identical snack street, and every city has started to create music fountains to attract tourists since the music fountain became popular.

In recent years, more and more people have chosen to travel abroad, such as Thailand and other Southeast Asian countries while the trend of domestic tourism is declining, especially in recent years, more and more tourists travel overseas to buy luxury goods, such as the Japanese toilet lid, which has been popular all over the country for 17 years. The reason is that our country's tourism products are not diversified, the products are not good enough, the products are not attractive enough and so on, so the supply demand of tourism market is not coordinated, It also led to more and more people like to travel abroad and buy things abroad.

\subsection{Tourism talent is scarce, scientific management level is not high}

In the past ten years, China's tourism market has been booming, but there are still not enough tourism talents to match it. All colleges and universities have tourism as a major, and the courses set up are also very diversified, such as tourism management, tour guide major, domestic 
tourism, tourism service, scenic spot development management, tourism marketing and so on. However, despite the large number of professional courses, few people go through professional examinations to engage in this industry. Almost graduation work is far from the major, which leads to more and more professional guides joining the tourism industry, It is also one of the reasons for the chaos of market order. Another very important reason is that the tourism industry in China has been booming since 10 years, the income of the tourism industry has also increased greatly[4], and the prospects of the tourism industry are still very considerable, but the fact is, despite the fact that the tourism industry is so attractive, But there are still not many people willing to engage in and seriously study the industry. From the point of view of setting up tourism specialty in colleges and universities, it is not difficult to find that the tourism specialty in our country is distributed in colleges and universities, and the key undergraduate schools rarely have this tourism specialty, and the distribution of resources is uneven. This has also produced a series of contradictions in China's

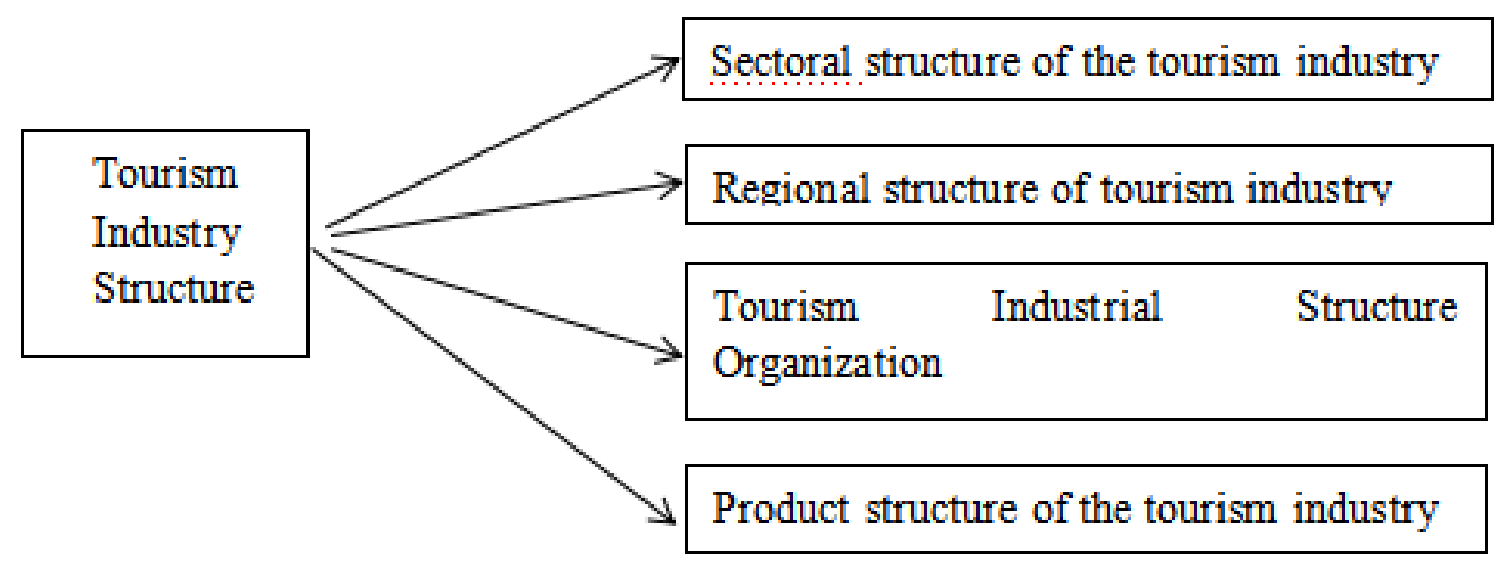

Figure 1. Tourism Industry Structure

\section{Discussion on Countermeasures to Promote Tourism Development in China}

\subsection{Strengthen market management and improve market order}

The rapid development of the Internet has brought great changes to all walks of life over the years. Under the background of the Internet, China's tourism industry has been singing along the way. In 2016, the State Council issued regulations to vigorously regulate the order of the tourism market, the government set up a number of tourism supervision and supervision departments, and local governments began to set up various institutions to maintain the order of the tourism market. The growth of these institutions in 16 years shows our determination to regulate the order of the tourism market. The major Internet platforms have brought convenience to the tourism industry, and in turn we should limit the false propaganda of the major tourism platforms, Secondly, the government should give full play to its ability, perfect our country's paid vacation system, innovate the system that does not accord with the current tourism market in tourism, and strengthen the realization of intelligent tourism as soon as possible[5].

\subsection{Strengthen the training of tourism professionals, use information technology to improve management}

The tourism industry of our country still has the unusual road to go, the tourism industry prospect is also very good, therefore each local government must attach importance to the tourism transmission industry this future also has the very great potential profession, increases the investment to the tourism talented person training, the tourism specialty construction not only enables each college and university, each key undergraduate university also should train, develops the tourism specialty into the trump card specialty, the government at all levels should also increase the investment to the university hardware and software equipment, trains the high quality, the diversification, the information elite talented person. The establishment of a regulatory management system using Internet technology to supervise the number of scenic spots, ensure the integrity of scenic spots, ensure the safety of consumers, use the Internet to strengthen the management of the tourism market, and make the tourism market order efficient and orderly [6].

\section{CONCLUSION}

It is no exaggeration to say that the tourism industry can be so hot and inseparable from the rapid development of the Internet. The Internet has brought opportunities and 
great challenges to the tourism industry. How to use the Internet to improve our tourism market system and make our tourism market better and better.

\section{REFERENCES}

1. Chen, Y.(2016)Building ecological civilization and modernizing national governance system and governance capacity [J].Chemical management.

2. Liao, Z.D.(20200A Study on Ideological and Political Reform of Tourism Management Specialty Curriculum — Taking "Tourism Marketing" as an Example[J].Heilongjiang Education (Higher Education Research and Assessment).

3. Cui, G.B.Zhen, Y.(2019)Exploration on the Teaching of Ideological and Political Science in Tourism Management Specialty Course _ Taking "Tourism of Tourism Resources as an Example[J].Contemporary Educational Practice and Teaching Research.

4. Fu, L.L. (2019) Research and Exploration on the Thought and Politics of Tourism Management Curriculum under the background of School-Enterprise Cooperation[J]. Journal of Beijing Printing Institute.

5. Liu, Y.X. (2019) Analysis on the Reform of Ideological and Political Teaching in the Course of Tourism Management in Independent College under the Background of Economic Globalization [J]. Marketing.

6. Xie, Y.P.(2020)A Preliminary Study on the Ideological and Political Construction of Tourism Management Specialty Course — Taking Guilin Tourism College as an Example[J].Journal of Hubei Open Vocational College. 